\title{
Penilaian Tingkat Kekumuhan Kawasan Permukiman di Tepian Air Kota Singkawang
}

\author{
Ely Nurhidayati ${ }^{\text {a }}$, Novi Safriadi ${ }^{b}$, Muhammad Faqih Dzulqarnain ${ }^{c}$ \\ a Universitas Tanjungpura, Pontianak, Indonesia \\ ${ }^{b}$ Universitas Tanjungpura, Pontianak, Indonesia \\ c Politeknik Aisyiyah Pontianak, Indonesia \\ E-mail Korespondensi: ely@untan.ac.id
}

\begin{abstract}
Abstrak: Perkembangan kota secara sporadis menyebabkan tidak terkendalinya lahan permukiman dan pola ruang Kota Singkawang, sehingga membentuk pola keterkaitan antar sistem perkotaan dan pengaruhnya berkontribusi terhadap berkembangnya kawasan permukiman kumuh. Permasalahannya adalah perkembangan permukiman ini justru meluas hingga ke pesisir dan tepian sungai. Adapun tujuan penelitian yaitu menilai tingkat kekumuhan kawasan permukiman di tepian air Kota Singkawang. Sasaran penelitian meliputi mengidentifikasi kawasan permukiman kumuh dan analisis skoring kawasan permukiman kumuh berdasarkan tujuh aspek. Metode penelitian yang digunakan adalah metode kualitatif berbasis data skoring dan interpretasi hasil skoring berdasarkan Peraturan Menteri PUPR RI Nomor 14/RT/M/2018 tentang Pencegahan dan Peningkatan Kualitas Terhadap Perumahan Kumuh dan Permukiman Kumuh. Hasil penelitian yang diperoleh meliputi kawasan permukiman tepian air yang terletak di pesisir yaitu Kelurahan Sedau, sedangkan permukiman tepian air yang terletak di tepian sungai yaitu Kelurahan Kuala dan Kelurahan Pasiran. Analisis skoring terhadap tujuh aspek menujukkan bahwa di Kelurahan Sedau RT39/RW7 memiliki tingkat kekumuhan ringan, Kelurahan Kuala RT10/RW3 memiliki tingkat kekumuhan ringan, dan Kelurahan Pasiran RT12/RW4 memiliki tingkat kekumuhan sedang.
\end{abstract}

Kata Kunci: permukiman, kumuh, tepi air, skoring

Abstract: The sporadic development of the city leads to uncontrolled residential land and the spatial pattern of Singkawang City, thus forming a pattern of linkages between urban systems and its influence contributing to the development of slum areas. The problem is that the development of these settlements extends to the coast and riverbanks. The research objective is to assess the slums of the residential area on the waterfront of Singkawang City. The research targets include identifying slum areas and scoring analysis of slum areas based on seven aspects. The research method used is a qualitative method based on scoring data and the interpretation of scoring results based on the Regulation of the Minister PUPR RI No 14 / RT / M / 2018 concerning Prevention and Quality Improvement of Slum Housing and Slum Settlements. The research results is the waterfront settlements located on the coast, namely Sedau Village, while waterfront settlements on the riverbank are Kelurahan Kuala and Kelurahan Pasiran. The scoring analysis of seven aspects shows that Kelurahan Sedau RT39 / RW7 has a light slum level. Kelurahan Kuala RT10 / RW3 has a light slum level, and Kelurahan Pasiran RT12 / RW4 has a moderate slum level.

Keywords : settlements, slums, riverbanks, scoring 


\section{PENDAHULUAN}

Kota Singkawang sebagai salah satu kota menengah di Provinsi Kalimantan Barat, yang menjadi bagian Kawasan strategis nasional juga mengalami beberapa permasalahan perkotaan sebagaimana yang dialami kota-kota lain di Indonesia yaitu Kawasan kumuh. Permukiman kumuh ditandai dengan kepadatan bangunan yang tinggi, kualitas permukiman yang buruk, perumahan dan status kepemilikan yang tidak aman dan kurangnya akses air bersih, sanitasi, dan infrastruktur (Sharma et al., 2020). Adapun penyebab kekumuhan di kawasan tepian air khususnya pesisir yaitu karakteristik sosial budaya, urbanisasi, keterbatasan lahan, kemudahan akses, prasarana dan sarana, serta kurang tegasnya kebijakan pemerintah (Nugroho, 2019). Menariknya justru permukiman tepian sungai justru harus dijaga, karena tidak semua permukiman kumuh perlu digusur (Michiani \& Asano, 2019). Oleh karena sebagian besar kota-kota di Indonesia tumbuh di kawasan tepian sungai, tetapi dalam perkembangan saat ini kota-kota tersebut cenderung hanya dilihat sebagai kota yang tidak tertata dengan baik (Rijanta et al., 2014).

Berdasarkan surat keputusan (SK) Walikota Singkawang nomor 600/70.A/PERUM-C Tahun 2016 Tentang Penetapan Lokasi Lingkungan Perumahan dan Permukiman Kumuh di Kota Singkawang, menyebutkan bahwa kawasan kumuh yang terdapat di Kota Singkawang sebanyak 6 kawasan lokasi kumuh dengan total luas 74,03 hektar yang tersebar di tiap kecamatan. Keberadaan kawasan kumuh tersebut di Kota Singkawang masih belum dapat sepenuhnya ditangani karena terkendala permasalahan teknis, politis dan pendanaan. Selain itu informasi kawasan-kawasan kumuh dalam SK Walikota tersebut juga belum secara detail menyampaikan kondisi lingkungan serta sebaran berupa peta lokasi kawasan kumuh yang ada di Kota Singkawang.

Dalam kaitannya dengan penelitian ini, penilaian tingkat kekumuhan kawasan permukiman di tepian air Kota Singkawang diperlukan untuk mengantisipasi tumbuhnya kawasan kumuh baru di tepian air. Selain itu, sebagai data dasar dalam mengidentifikasi eksisting kawasan kumuh yang disebutkan dalam Peraturan Menteri PUPR RI Nomor 14/RT/M/2018 tentang Pencegahan dan Peningkatan Kualitas Terhadap Perumahan Kumuh dan Permukiman Kumuh. Konsep dasar peningkatan kualitas fisik permukiman kumuh terdiri atas tiga elemen antara lain pengaturan jaringan jalan, meningkatkan utilitas publik, dan menyediakan ruang dan fasilitas yang nyaman (Michiani \& Asano, 2019). Adapun lokasi penelitian dibatasi di 3 (tiga) kelurahan, meliputi Kelurahan Sedau, Kelurahan Kuala, dan Kelurahan Pasiran. Secara keseluruhan sebaran perumahan kumuh dan permukiman kumuh di Kota Singawang dapat dilihat pada gambar 1.

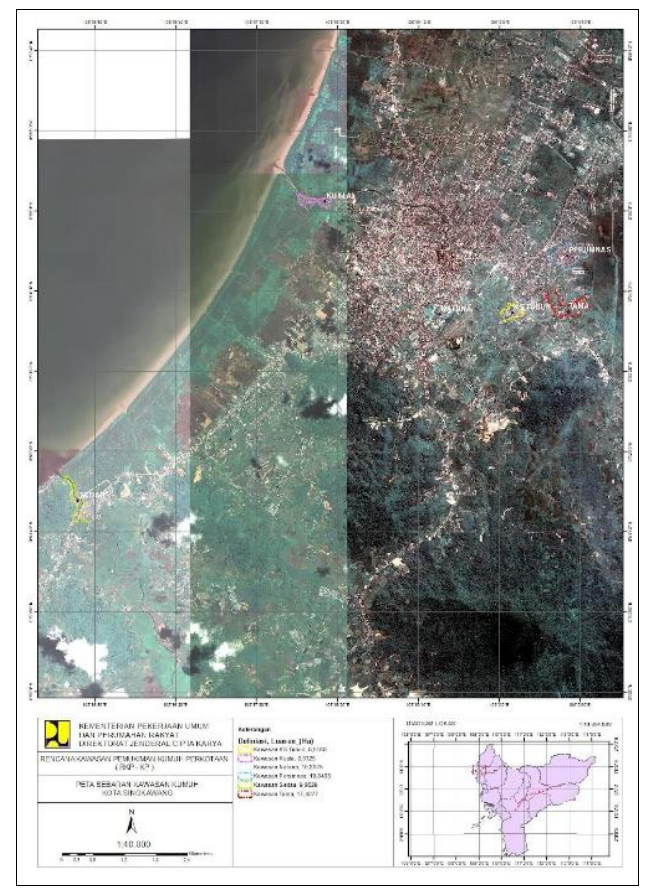

Gambar 1 Peta Sebaran Lokasi Perumahan dan Permukiman Kumuh Kota Singkawang 
Penelitian ini menggunakan metode penelitian kualitatif melalui interpretasi hasil skoring lokasi penelitian berdasarkan Peraturan Menteri PUPR RI Nomor 14/RT/M/2018 tentang Pencegahan dan Peningkatan Kualitas Terhadap Perumahan Kumuh dan Permukiman Kumuh. Pengumpulan data primer dilakukan berupa penelitian langsung di lapangan untuk melengkapi data yang diperlukan seperti melakukan observasi di lapangan terkait objek penelitian.

Data tersebut antar lain lokasi kawasna permukiman kumuh sesuai SK Walikota Singkawang nomor 600/70.A/PERUM-C Tahun 2016, data format isian identifikasi lokasi permukiman kumuh sesuai Permen PUPR RI No 14 / RT / M / 2018 tentang Pencegahan dan Peningkatan Kualitas Terhadap Perumahan Kumuh dan Permukiman Kumuh. Sedangkan data sekunder berupa literatur-literatur dan Peraturan serta SK yang berkaitan dengan permukiman kumuh, data arsip tim Kotaku yang mendukung penelitian berupa data permukiman kumuh yang telah dilakukan sebelumnya.

\section{DATA DAN METODE}

\subsection{Area penelitian}

Lingkungan perumahan dan permukiman kumuh merupakan satuan lingkungan dalam lingkup wilayah kota yang dinilai tidak laik huni karena ketidakteraturan bangunan, tingkat kepadatan bangunan yang tinggi, dan kualitas bangunan serta sarana dan prasarana yang tidak memenuhi syarat. Perubahan Lokasi Lingkungan Perumahan dan Permukiman Kumuh ditetapkan berdasarkan hasil pendataan yang dilakukan oleh Pemerintah Kota Singkawang dengan melibatkan peran masyarakat menggunakan ketentuan Tata Cara Penetapan Lokasi sebagaimana sesuai dengan Panduan Teknis Percepatan Penanganan Permukiman Kumuh di Perkotaan Berbasis Pemberdayaan Masyarakat.

Lokasi Perumahan Kumuh dan Permukiman Kumuh di Kota Singkawang ditetapkan sebagai dasar penyusunan Rencana Aksi Peningkatan Kualitas Perumahan Kumuh dan Permukiman Kumuh di Kota Singkawang, yang merupakan komitmen Pemerintah Daerah dalam mendukung Program Nasional Pengentasan Permukiman Kumuh, termasuk dalam hal ini Target Nasional Permukiman Tanpa Kumuh. Berdasarkan Keputusan Walikota Singkawang Nomor 600/70. A/Perum-C Tahun 2016 tentang Penetapan Lokasi Lingkungan Perumahan Dan Permukiman Kumuh Di Kota Singkawang, lokasi Perumahan dan Permukiman Kumuh di Kota Singkawang meliputi sejumlah 6 (enam) kawasan, di 3 (tiga) kecamatan dengan luas total kawasan kumuh sebesar 74,03 (tujuh puluh empat koma nol tiga) hektar.

Tabel 1 Daftar Lokasi Perumahan Kumuh dan Permukiman Kumuh

\begin{tabular}{|c|l|r|r|}
\hline No & \multicolumn{1}{|c|}{ Lokasi } & $\begin{array}{r}\text { Luas } \\
\text { (Hektar) }\end{array}$ & $\begin{array}{r}\text { Tingkat } \\
\text { Kekumuhan }\end{array}$ \\
\hline 1 & $\begin{array}{l}\text { Kawasan Kom Yos Sudarso, Kelurahan Kuala } \\
\text { Kecamatan Singkawang Barat }\end{array}$ & 8.03 & Sedang \\
\hline 2 & $\begin{array}{l}\text { Kawasan Tama, Kelurahan Roban } \\
\text { Kecamatan Singkawang Tengah }\end{array}$ & 17.42 & Sedang \\
\hline 3 & $\begin{array}{l}\text { Kawasan K.S. Tubun, Kelurahan Roban } \\
\text { Kecamatan Singkawang Tengan }\end{array}$ & 8.51 & Sedang \\
\hline 4 & $\begin{array}{l}\text { Kawasan Natuna, Kelurahan Pasiran } \\
\text { Kecamatan Singkawang Barat }\end{array}$ \\
\hline 5 & $\begin{array}{l}\text { Kawasan Komplek Perumahan Roban } \\
\text { Kecamatan Singkawang Tengah }\end{array}$ & 10.28 & Sedang \\
\hline 6 & $\begin{array}{l}\text { Kawasan Sedau, Kelurahan Sedau } \\
\text { Kecamatan Singkawang Selatan }\end{array}$ & 19.84 & Sedang \\
\hline
\end{tabular}

Sumber: Dinas Perkimtah Singkawang, 2016

\subsection{Tahapan Penelitian}

Penelitian ini menggunakan metode penelitian kualitatif melalui interpretasi hasil skoring lokasi penelitian berdasarkan Peraturan Menteri PUPR RI Nomor 14/RT/M/2018 tentang Pencegahan dan 
Peningkatan Kualitas Terhadap Perumahan Kumuh dan Permukiman Kumuh. Adapun tahapan penelitian ini antara lain persiapan, pengumpulan data, pengolahan dan analisis data sebagai berikut.

A. Persiapan

Tahap persiapan ini berupa persiapan awal sebelum melakukan penelitian yaitu berupa studi pustaka untuk mengumpulkan informasi yang berkaitan dengan masalah atau topik yang menjadi objek penelitian, serta survei awal ke Kelurahan Sedau, Kelurahan Kuala, dan Kelurahan Pasiran Kota Singkawang untuk mengamati secara langsung kondisi eksisting permukiman kumuh di tepian air.

B. Pengumpulan Data

1. Data Primer

Pengumpulan data primer dilakukan berupa penelitian langsung di lapangan untuk melengkapi data yang diperlukan seperti melakukan observasi di lapangan terkait objek penelitian yang dibahas, menentukan lokasi pengamatan untuk mengambil data-data yang diperlukan terhadap penyelesaian masalah penelitian, dan pengambilan dokumentasi.

- Lokasi kawasan permukiman kumuh

Lokasi kawasan permukiman kumuh disurat keputusan (SK) Walikota Singkawang nomor: 600/70.A/PERUM-C Tahun 2016 Tentang Penetapan Lokasi Lingkungan Perumahan dan Permukiman Kumuh di Kota Singkawang.

- Format isian identifikasi lokasi permukiman kumuh

Untuk mengisi identifikasi lokasi permukiman kumuh mengacu pada Peraturan Menteri Pekerjaan Umum dan Perumahan Rakyat Repulik Indonesia Nomor 14/PRT/M/2018 Tentang Pencegahan dan Peningkatan Kualitas Terhadap Perumahan Kumuh dan Permukiman Kumuh.

2. Data Sekunder

Data sekunder merupakan data yang dikumpulkan untuk melengkapi terkait dengan penelitian. Data sekunder berupa literatur-literatur dan Peraturan serta SK yang berkaitan dengan permukiman kumuh, data arsip tim Kotaku yang mendukung penelitian berupa data permukiman kumuh yang telah dilakukan sebelumnya.

C. Pengolahan dan Analisis Data

Pengolahan data dilakukan setelah semua data primer dan data sekunder terkumpul. Data yang telah terkumpul selanjutnya dilakukan penilaian lokasi menggunakan formulasi yang mengacu pada Peraturan Menteri Pekerjaan Umum dan Perumahan Rakyat Repulik Indonesia Nomor 14/PRT/M/2018 Tentang Pencegahan dan Peningkatan Kualitas Terhadap Perumahan Kumuh dan Permukiman Kumuh. Adapun cakupan penilaian lokasi meliputi, identifikasi kondisi kekumuhan, identifikasi legalitas lahan, dan identifikasi pertimbangan lain seperti pada gambar 2.

1. Identifikasi kondisi kekumuhan, meliputi 16 (enam belas) kriteria yang terhimpun dalam 7 aspek, yaitu:

a. Aspek Kondisi Bangunan Gedung, dengan kriteria:

1. Ketidakteraturan Bangunan; Tingkat Kepadatan Bangunan; dan

2. Ketidaksesuaian dengan Persyaratan Teknis Bangunan.

b. Aspek Kondisi Jalan Lingkungan, dengna kriteria:

1. Jaringan jalan lingkungan tidak melayani seluruh lingkungan perumahan atau permukiman;

2. Kualitas Permukaan Jalan Lingkungan yang buruk.

c. Aspek Kondisi Penyediaan Air Minum, dengan kriteria:

1. akses aman air minum tidak tersedia; dan

2. kebutuhan air minum minimal setiap individu tidak terpenuhi.

d. Aspek Kondisi Drainase Lingkungan, dengan kriteria:

1. drainase lingkungan tidak tersedia;

2. drainase lingkungan tidak mampu mengalirkan limpasan air hujan sehingga menimbulkan genangan; dan

3. kualitas konstruksi drainase lingkungan buruk.

e. Aspek Kondisi Pengelolaan Air Limbah, dengan kriteria:

1. sistem pengelolaan air limbah tidak memenuhi persyaratan teknis; dan

2. prasarana dan sarana pengelolaan air limbah tidak memenuhi persyaratan teknis.

f. Aspek Kondisi Pengelolaan Persampahan, dengan kriteria: 
1. prasarana dan sarana persampahan tidak memenuhi dengan persyaratan teknis; dan

2. sistem pengelolaan persampahan tidak memenuhi persyaratan teknis.

g. Aspek Kondisi Proteksi Kebakaran, dengna kriteria:

1. prasarana proteksi kebakaran tidak tersedia;

2. sarana proteksi kebakaran tidak tersedia.

2. Identifikasi legalitas lahan, meliputi Kejelasan Status Penguasaan Lahan dan Kesesuaian Rencana Tata Ruang (RTR).

3. Identifikasi pertimbangan lain, meliputi nilai stretegis lokasi, kependudukan dan kondisi sosial, ekonomi dan budaya.

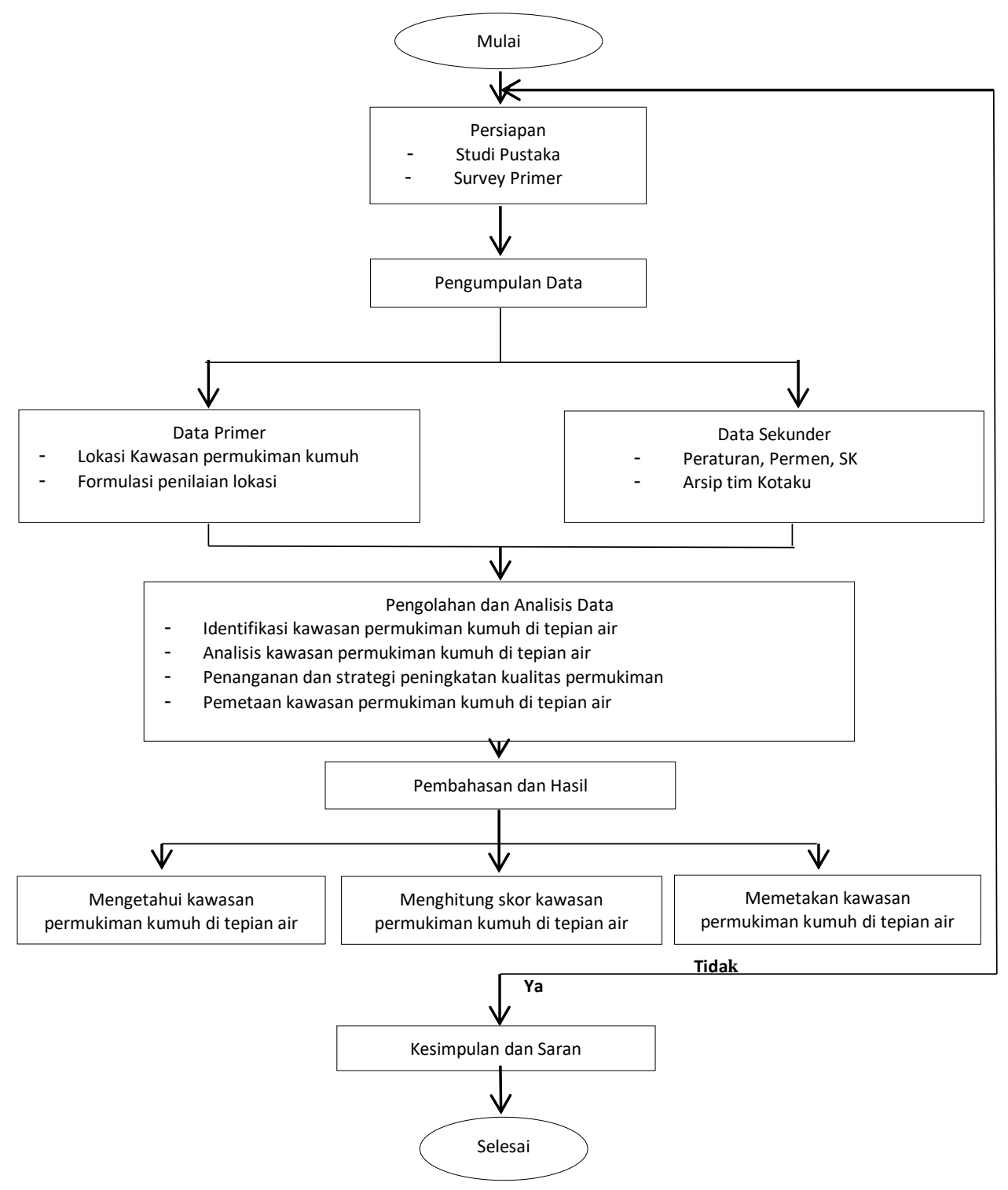

Gambar 2 Diagram Alir Penelitian

\section{HASIL DAN PEMBAHASAN}

3.1 Tepian Pesisir

3.1.1 Kawasan Permukiman Kumuh Kelurahan Sedau RT39/RW7

Permukiman di tepian air kawasan pesisir terletak di Kelurahan Sedau RT39/RW7 Kecamatan Singkawang Selatan, Kota Singkawang, Kalimantan Barat. Kawasan ini memiliki luas permukiman kumuh sebesar 8,57 Ha, jumlah bangunan sebanyak 140 unit, jumlah penduduk berjumlah 642 jiwa, dan jumlah KK 
sebanyak 167 KK. Adapun profil wilayah permukiman kumuh di tepian pesisir dapat dilihat pada tabel 1 dan gambar 3.

Tabel 2 Profil Wilayah Kelurahan Sedau RT39/RW7

\begin{tabular}{|c|c|c|c|c|c|}
\hline \multirow{2}{*}{ ASPEK } & \multirow{2}{*}{ KRITERIA } & \multicolumn{4}{|c|}{ KONDISI AWAL (BASELINE) } \\
\hline & & NUMERIK & SATUAN & $\begin{array}{l}\text { PROSEN } \\
(\%)\end{array}$ & NILAI \\
\hline \multirow{3}{*}{$\begin{array}{l}\text { 1. KONDISI } \\
\text { BANGUNAN } \\
\text { GEDUNG }\end{array}$} & a. Ketidakteraturan Bangunan & 140,00 & Unit & $100,00 \%$ & 5 \\
\hline & b. Kepadatan Bangunan & - & $\mathrm{Ha}$ & $0,00 \%$ & 0 \\
\hline & $\begin{array}{l}\text { c. Ketidaksesuaian dengan Persy Teknis } \\
\text { Bangunan }\end{array}$ & 3,00 & Unit & $2,14 \%$ & 0 \\
\hline \multicolumn{2}{|c|}{ Rata-rata Kondisi Bangunan Gedung } & & & $33,33 \%$ & \\
\hline \multirow{2}{*}{$\begin{array}{l}\text { 2. Kondisi Jalan } \\
\text { Lingkungan }\end{array}$} & a. Cakupan Pelayanan Jalan Lingkungan & 58,00 & Meter & $1,12 \%$ & 0 \\
\hline & b. Kualitas Permukaan Jalan lingkungan & 936,00 & Meter & $18,01 \%$ & 0 \\
\hline \multicolumn{2}{|c|}{ Rata-rata Kondisi Jalan Lingkungan } & & & $0,00 \%$ & \\
\hline \multirow{2}{*}{$\begin{array}{l}\text { 3. Kondisi } \\
\text { Penyediaan Air } \\
\text { Minum }\end{array}$} & a. Ketersediaan Akses Aman Air Minum & 5,00 & KK & $2,99 \%$ & 0 \\
\hline & $\begin{array}{l}\text { b. Tidak terpenuhinya Kebutuhan Air } \\
\text { Minum }\end{array}$ & 2,00 & KK & $1,20 \%$ & 0 \\
\hline \multicolumn{2}{|c|}{ Rata-rata Kondisi Penyediaan Air Minum } & & & $0,00 \%$ & \\
\hline \multirow{3}{*}{$\begin{array}{l}\text { 4. Kondisi } \\
\text { Drainase } \\
\text { Lingkungan }\end{array}$} & $\begin{array}{l}\text { a. Ketidakmampuan Mengalirkan Limpasan } \\
\text { Air }\end{array}$ & - & $\mathrm{Ha}$ & $0,00 \%$ & 0 \\
\hline & b. Ketidaktersediaan Drainase & 931,00 & Meter & $55,55 \%$ & 3 \\
\hline & c. Kualitas Konstruksi Drainase & 598,00 & Meter & $35,68 \%$ & 1 \\
\hline \multicolumn{2}{|c|}{ Rata-rata Kondisi Drainase Lingkungan } & & & $30,41 \%$ & \\
\hline \multirow{2}{*}{$\begin{array}{l}\text { 5. Kondisi } \\
\text { Pengelolaan Air } \\
\text { Limbah }\end{array}$} & $\begin{array}{l}\text { a. Sistem Pengelolaan Air Limbah Tidak } \\
\text { Sesuai Standar Teknis }\end{array}$ & - & KK & $0,00 \%$ & 0 \\
\hline & $\begin{array}{l}\text { b. Prasarana dan Sarana Pengelolaan Air } \\
\text { Limbah Tidak Sesuai dengan Persyaratan } \\
\text { Teknis }\end{array}$ & - & KK & $0,00 \%$ & 0 \\
\hline \multicolumn{2}{|c|}{ Rata-rata Kondisi Penyediaan Air Limbah } & & & $0,00 \%$ & \\
\hline \multirow{2}{*}{$\begin{array}{l}\text { 6. Kondisi } \\
\text { Pengelolaan } \\
\text { Persampahan }\end{array}$} & $\begin{array}{l}\text { a. Prasarana dan Sarana Persampahan } \\
\text { Tidak Sesuai dengan persyaratan Teknis }\end{array}$ & 167,00 & KK & $100,00 \%$ & 5 \\
\hline & $\begin{array}{l}\text { b. Sistem Pengelolaan Persampahan yang } \\
\text { tidak sesuai Standar Teknis }\end{array}$ & - & KK & $0,00 \%$ & 0 \\
\hline \multicolumn{2}{|c|}{ Rata-rata Kondisi Pengelolaan Persampahan } & & & $50,00 \%$ & \\
\hline \multirow{2}{*}{$\begin{array}{l}\text { 7. Kondisi } \\
\text { Proteksi } \\
\text { Kebakaran }\end{array}$} & $\begin{array}{l}\text { a. Ketidaktersediaan Prasarana Proteksi } \\
\text { Kebakaran }\end{array}$ & 140,00 & Unit & $100,00 \%$ & 5 \\
\hline & $\begin{array}{l}\text { b. Ketidaktersediaan Sarana Proteksi } \\
\text { Kebakaran }\end{array}$ & 140,00 & Unit & $100,00 \%$ & 5 \\
\hline \multicolumn{2}{|c|}{ Rata-rata Kondisi Proteksi Kebakaran } & & & $100,00 \%$ & \\
\hline
\end{tabular}




\begin{tabular}{|r|c|} 
TOTAL NILAI & 24 \\
\hline TINGKAT KEKUMUHAN & $\begin{array}{r}\text { KUMUH } \\
\text { RINGAN }\end{array}$ \\
\hline RATA2 KEKUMUHAN SEKTORAL & $30,53 \%$ \\
\hline KONTRIBUSI PENANGANAN & $0,00 \%$ \\
\hline
\end{tabular}

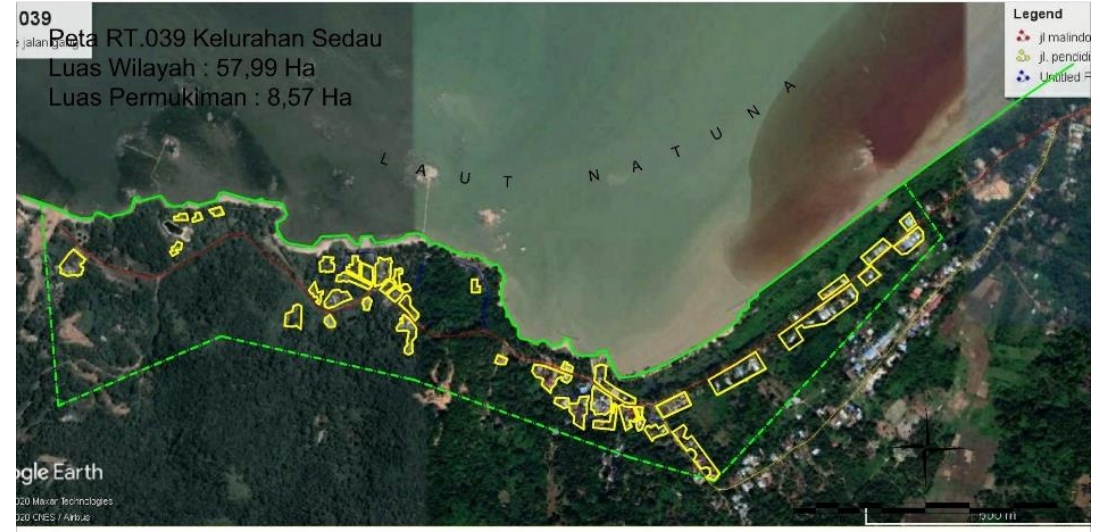

(a)

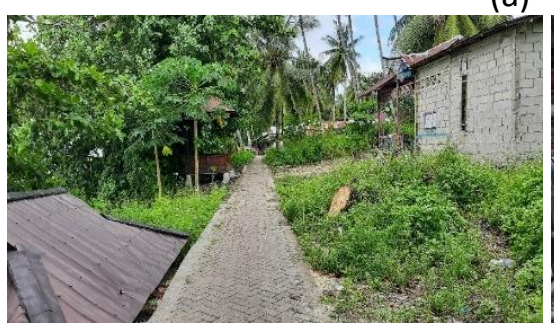

(c)

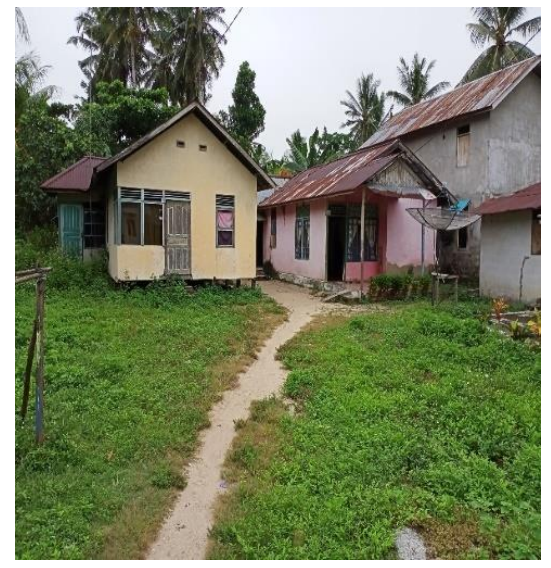

(b)

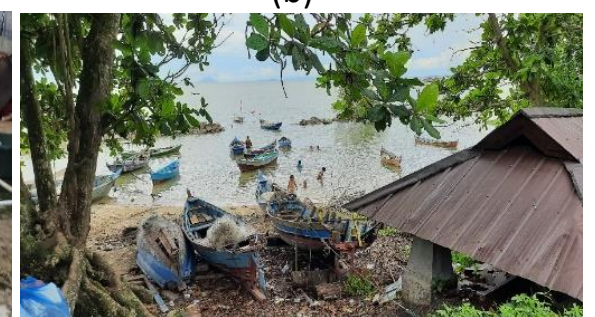

(e)

Gambar 3 Permukiman Kumuh Wilayah Pesisir Kelurahan Sedau RT39/RW7

(b) Peta Permukiman Kumuh; (b) Kondisi Rumah; (c) Kondisi Jalan Lingkungan; (d) Kondisi Drainase; (e) Sosial Ekonomi

\subsection{Tepian Sungai}

3.2.1 Kawasan Permukiman Kumuh Kelurahan Kuala RT10/RW3

Permukiman di tepian air kawasan sungai terletak di Kelurahan Kuala RT10/RW3 Kecamatan Singkawang Barat, Kota Singkawang, Kalimantan Barat. Kawasan ini memiliki luas permukiman kumuh sebesar 0,68 $\mathrm{Ha}$, jumlah bangunan sebanyak 37unit, jumlah penduduk berjumlah 188 jiwa, dan jumlah KK sebanyak 52 KK. Adapun profil wilayah permukiman kumuh di tepian sungai dapat dilihat pada tabel 3 dan gambar 4.

Tabel 3 Profil Wilayah Kelurahan Kuala RT10/RW3

\begin{tabular}{|c|c|c|c|c|c|}
\hline \multirow{2}{*}{ ASPEK } & \multirow{2}{*}{ KRITERIA } & \multicolumn{4}{|c|}{ KONDISI AWAL (BASELINE) } \\
\hline & & NUMERIK & SATUAN & PROSEN (\%) & NILAI \\
\hline \multirow{2}{*}{$\begin{array}{l}\text { 1. KONDISI } \\
\text { BANGUNAN } \\
\text { GEDUNG }\end{array}$} & $\begin{array}{l}\text { a. Ketidakteraturan } \\
\text { Bangunan }\end{array}$ & 37,00 & Unit & $100,00 \%$ & 5 \\
\hline & b. Kepadatan Bangunan & - & $\mathrm{Ha}$ & $0,00 \%$ & 0 \\
\hline
\end{tabular}




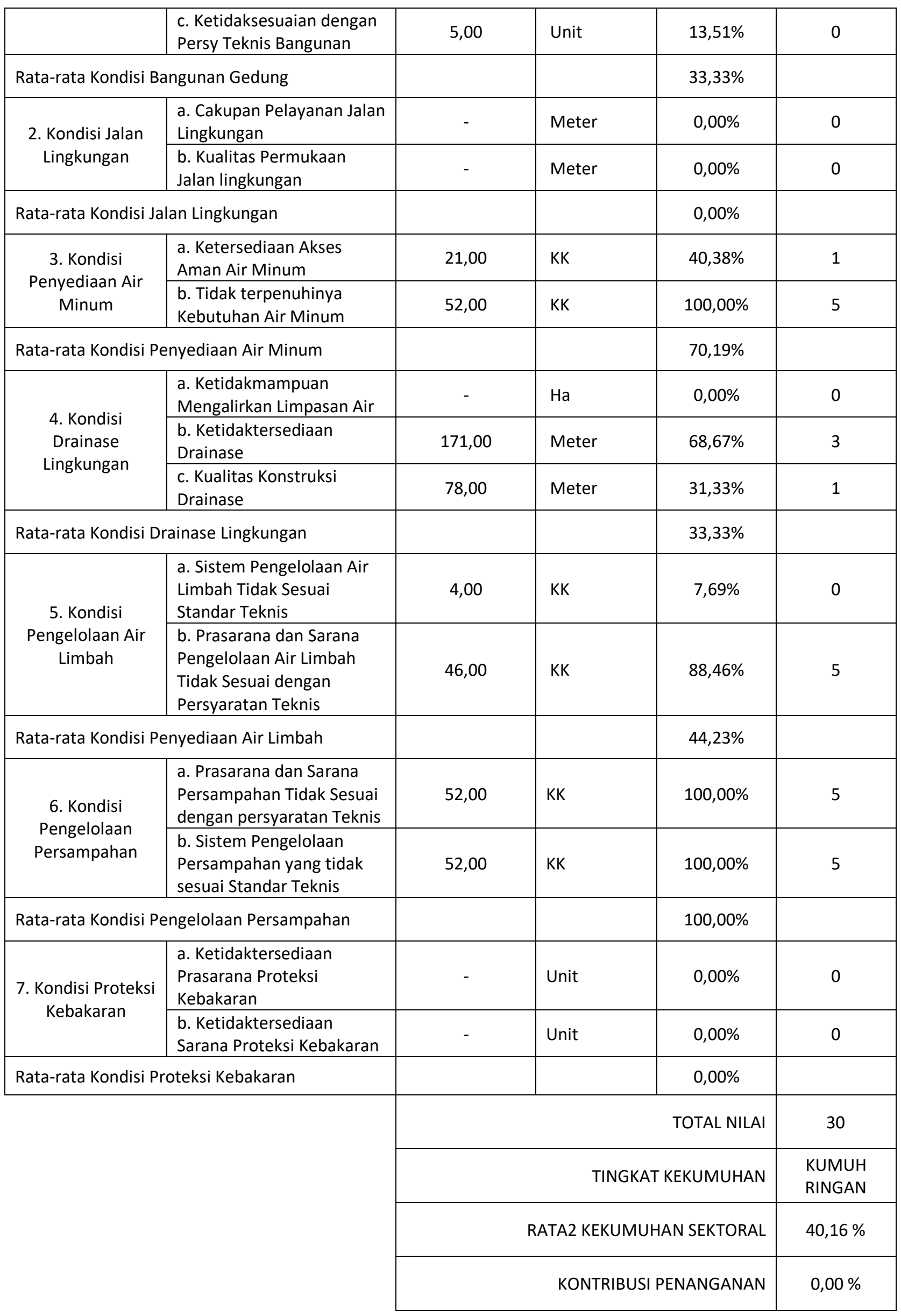




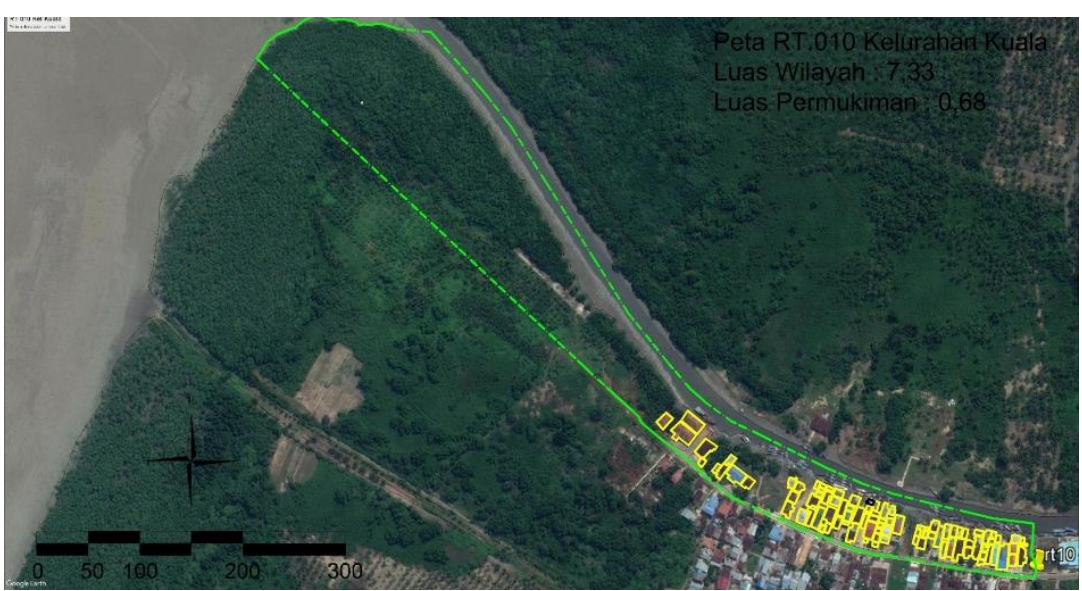

(a)

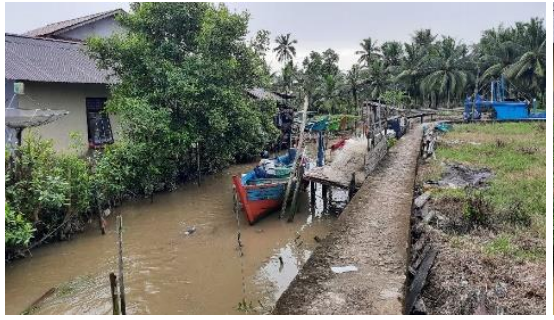

(c)

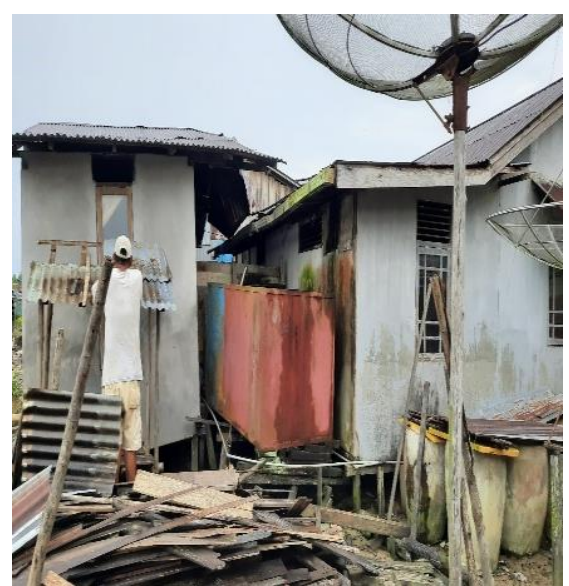

(b)

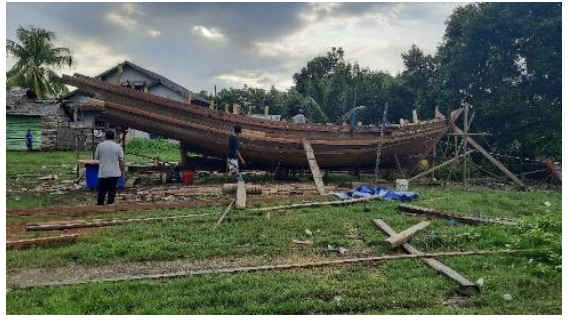

(e)

Gambar 4 Permukiman Kumuh Wilayah Pesisir Kelurahan Kuala RT10/RW3

(b) Peta Permukiman Kumuh; (b) Kondisi Rumah; (c) Kondisi Jalan Lingkungan; (d) Kondisi Drainase; (e) Sosial Ekonomi

\subsubsection{Kawasan Permukiman Kumuh Kelurahan Pasiran RT12/RW4}

Permukiman di tepian air kawasan pesisir terletak di Kelurahan Pasiran RT12/RW4 Kecamatan Singkawang Barat, Kota Singkawang, Kalimantan Barat. Kawasan ini memiliki luas permukiman kumuh sebesar 1,00 Ha, jumlah bangunan sebanyak 41 unit, jumlah penduduk berjumlah 155 jiwa, dan jumlah KK sebanyak $42 \mathrm{KK}$. Adapun profil wilayah permukiman kumuh di tepian pesisir dapat dilihat pada tabel 3 dan gambar 5.

Tabel 4 Profil Wilayah Kelurahan Pasiran RT12/RW4

\begin{tabular}{|c|c|c|c|c|c|}
\hline \multirow{2}{*}{ ASPEK } & \multirow{2}{*}{ KRITERIA } & \multicolumn{4}{|c|}{ KONDISI AWAL (BASELINE) } \\
\hline & & NUMERIK & SATUAN & PROSEN (\%) & NILAI \\
\hline \multirow{3}{*}{$\begin{array}{l}\text { 1. KONDISI } \\
\text { BANGUNAN } \\
\text { GEDUNG }\end{array}$} & $\begin{array}{l}\text { a. Ketidakteraturan } \\
\text { Bangunan }\end{array}$ & 41,00 & Unit & $100,00 \%$ & 5 \\
\hline & b. Kepadatan Bangunan & - & $\mathrm{Ha}$ & $0,00 \%$ & 0 \\
\hline & $\begin{array}{l}\text { c. Ketidaksesuaian dengan } \\
\text { Persy Teknis Bangunan }\end{array}$ & 41,00 & Unit & $100,00 \%$ & 5 \\
\hline \multicolumn{2}{|c|}{ Rata-rata Kondisi Bangunan Gedung } & & & $66,67 \%$ & \\
\hline \multirow{2}{*}{$\begin{array}{l}\text { 2. Kondisi Jalan } \\
\text { Lingkungan }\end{array}$} & $\begin{array}{l}\text { a. Cakupan Pelayanan } \\
\text { Jalan Lingkungan }\end{array}$ & - & Meter & $0,00 \%$ & 0 \\
\hline & $\begin{array}{l}\text { b. Kualitas Permukaan } \\
\text { Jalan lingkungan }\end{array}$ & - & Meter & $0,00 \%$ & 0 \\
\hline \multicolumn{2}{|c|}{ Rata-rata Kondisi Jalan Lingkungan } & & & $0,00 \%$ & \\
\hline $\begin{array}{c}\text { 3. Kondisi } \\
\text { Penyediaan Air }\end{array}$ & $\begin{array}{l}\text { a. Ketersediaan Akses } \\
\text { Aman Air Minum }\end{array}$ & - & KK & $0,00 \%$ & 0 \\
\hline
\end{tabular}




\begin{tabular}{|c|c|c|c|c|c|}
\hline Minum & $\begin{array}{l}\text { b. Tidak terpenuhinya } \\
\text { Kebutuhan Air Minum }\end{array}$ & 42,00 & KK & $100,00 \%$ & 5 \\
\hline \multicolumn{2}{|c|}{ Rata-rata Kondisi Penyediaan Air Minum } & & & $50,00 \%$ & \\
\hline \multirow{3}{*}{$\begin{array}{l}\text { 4. Kondisi } \\
\text { Drainase } \\
\text { Lingkungan }\end{array}$} & $\begin{array}{l}\text { a. Ketidakmampuan } \\
\text { Mengalirkan Limpasan Air }\end{array}$ & 1,00 & $\mathrm{Ha}$ & $100,00 \%$ & 5 \\
\hline & $\begin{array}{l}\text { b. Ketidaktersediaan } \\
\text { Drainase }\end{array}$ & - & Meter & $0,00 \%$ & 0 \\
\hline & $\begin{array}{l}\text { c. Kualitas Konstruksi } \\
\text { Drainase }\end{array}$ & 61,00 & Meter & $100,00 \%$ & 5 \\
\hline \multicolumn{2}{|c|}{ Rata-rata Kondisi Drainase Lingkungan } & & & $66,67 \%$ & \\
\hline \multirow{2}{*}{$\begin{array}{l}\text { 5. Kondisi } \\
\text { Pengelolaan Air } \\
\text { Limbah }\end{array}$} & $\begin{array}{l}\text { a. Sistem Pengelolaan Air } \\
\text { Limbah Tidak Sesuai } \\
\text { Standar Teknis }\end{array}$ & 42,00 & KK & $100,00 \%$ & 5 \\
\hline & $\begin{array}{l}\text { b. Prasarana dan Sarana } \\
\text { Pengelolaan Air Limbah } \\
\text { Tidak Sesuai dengan } \\
\text { Persyaratan Teknis }\end{array}$ & 42,00 & KK & $100,00 \%$ & 5 \\
\hline \multicolumn{2}{|c|}{ Rata-rata Kondisi Penyediaan Air Limbah } & & & $100,00 \%$ & \\
\hline \multirow{2}{*}{$\begin{array}{l}\text { 6. Kondisi } \\
\text { Pengelolaan } \\
\text { Persampahan }\end{array}$} & $\begin{array}{l}\text { a. Prasarana dan Sarana } \\
\text { Persampahan Tidak Sesuai } \\
\text { dengan persyaratan Teknis }\end{array}$ & 42,00 & KK & $100,00 \%$ & 5 \\
\hline & $\begin{array}{l}\text { b. Sistem Pengelolaan } \\
\text { Persampahan yang tidak } \\
\text { sesuai Standar Teknis }\end{array}$ & 42,00 & KK & $100,00 \%$ & 5 \\
\hline \multicolumn{2}{|c|}{ Rata-rata Kondisi Pengelolaan Persampahan } & & & $100,00 \%$ & \\
\hline \multirow{2}{*}{$\begin{array}{l}\text { 7. Kondisi Proteksi } \\
\text { Kebakaran }\end{array}$} & $\begin{array}{l}\text { a. Ketidaktersediaan } \\
\text { Prasarana Proteksi } \\
\text { Kebakaran }\end{array}$ & - & Unit & $0,00 \%$ & 0 \\
\hline & $\begin{array}{l}\text { b. Ketidaktersediaan } \\
\text { Sarana Proteksi Kebakaran }\end{array}$ & - & Unit & $0,00 \%$ & 0 \\
\hline \multicolumn{2}{|c|}{ Rata-rata Kondisi Proteksi Kebakaran } & & & $0,00 \%$ & \\
\hline & & & & TOTAL NILAI & 45 \\
\hline & & & \multicolumn{2}{|c|}{ TINGKAT KEKUMUHAN } & $\begin{array}{l}\text { KUMUH } \\
\text { SEDANG }\end{array}$ \\
\hline & & & \multicolumn{2}{|c|}{ RATA2 KEKUMUHAN SEKTORAL } & $54,76 \%$ \\
\hline & & & \multicolumn{2}{|c|}{ KONTRIBUSI PENANGANAN } & $0,00 \%$ \\
\hline
\end{tabular}




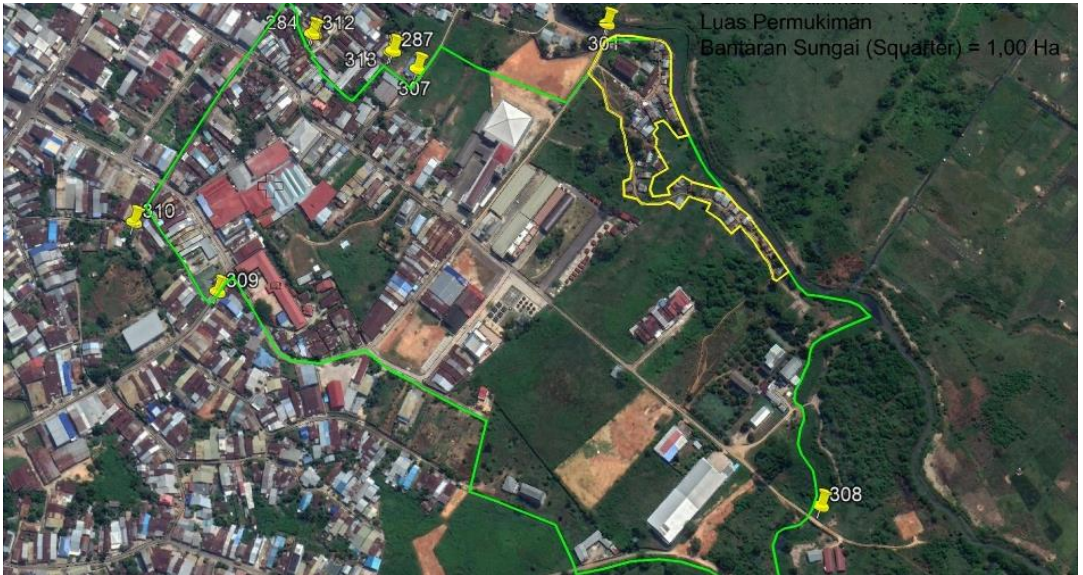

(a)

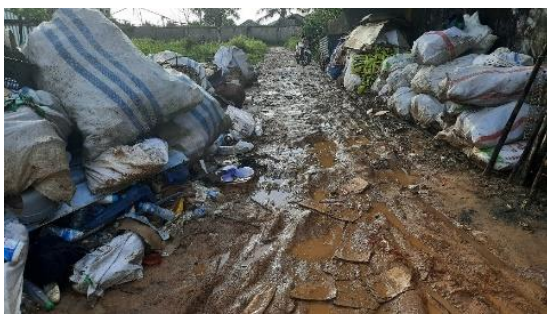

(c)

(d)

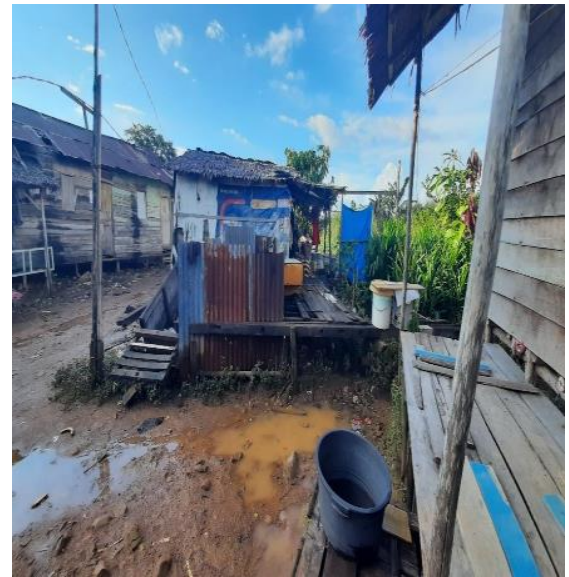

(b)

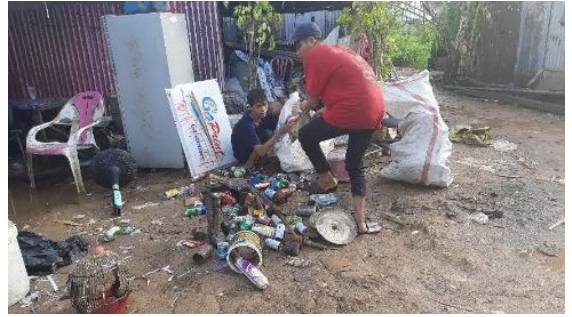

(e)

Gambar 5 Permukiman Kumuh Wilayah Pesisir Kelurahan Pasiran RT12/RW4

(b) Peta Permukiman Kumuh; (b) Kondisi Rumah; (c) Kondisi Jalan Lingkungan; (d) Kondisi Drainase; (e) Sosial Ekonomi

\section{KESIMPULAN}

Hasil identifikasi lokasi permukimkan kumuh di tepian air Kota Singkawang terdiri atas kawasan pesisir yaitu Kelurahan Sedau RT39/RW7, dan kawasan sungai yaitu Kelurahan Kuala RT10/RW3 dan Kelurahan Pasiran RT12/RW4. Berdasarkan hasil analisis skoring tingkat kekumuhan terhadap tujuh aspek menujukkan bahwa di Kelurahan Sedau RT39/RW7 memiliki tingkat kekumuhan ringan, Kelurahan Kuala RT10/RW3 memiliki tingkat kekumuhan ringan, dan Kelurahan Pasiran RT12/RW4 memiliki tingkat kekumuhan sedang.

Total luas kawasan permukiman kumuh di Kelurahan Sedau RT39/RW7 sebesar 8,57 Ha, jumlah bangunan sebanyak 140 unit, jumlah penduduk berjumlah 642 jiwa, dan jumlah KK sebanyak $167 \mathrm{KK}$. Total luas kawasan permukiman kumuh di Kelurahan Kuala RT12/RW4 sebesar 0,68 Ha, jumlah bangunan sebanyak 37unit, jumlah penduduk berjumlah 188 jiwa, dan jumlah KK sebanyak 52 KK. Sedangkan total luas kawasan permukiman kumuh di Kelurahan Pasiran RT12/RW4 sebesar 1,00 Ha, jumlah bangunan sebanyak 41 unit, jumlah penduduk berjumlah 155 jiwa, dan jumlah KK sebanyak 42 KK.

Penelitian ini masih terbatas pada beberapa wilayah di Kelurahan Sedau, Kelurahan Kuala dan Kelurahan Pasiran. Adapun klasifikasi pemetaan hanya sebatas deliniasi kawasan permukiman kumuh di tepian air secara mendalam baik pada aspek identifikasi dan analisisnya sesuai dengan Peraturan Menteri Pekerjaan Umum dan Perumahan Nomor 14 Tahun 2018 tentang Pencegahan dan Peningkatan Kualitas Terhadap Perumahan Kumuh dan Permukiman Kumuh. Sehingga untuk penelitian berikutnya dilakukan pengklasifikasian permukiman kumuh pada unit amatan lainnya. Selain itu diharapkan penelitian lanjutan tentang pencegahan indikasi munculnya perkembangan lokasi kumuh-kumuh baru, sehingga dapat direkomendasikan langkah-langkah strategis dalam penanganannya di samping untuk pengendalian kawasan kumuh agar tidak berkembang dan sesuai dengan arahan peruntukan tata ruangnya.

\section{DAFTAR PUSTAKA}

Badan Pusat Statistik Kota Singkawang. 2019. Kota Singkawang Dalam Angka 2019. Kalimantan Barat. Budiharjo, Eko. 1997. Tata Ruang Perkotaan. Bandung: Alumni. 
Michiani, M. V., \& Asano, J. (2019). Physical upgrading plan for slum riverside settlement in traditional area: A case study in Kuin Utara, Banjarmasin, Indonesia. Frontiers of Architectural Research, 8(3), 378-395. https://doi.org/10.1016/j.foar.2019.03.005

Nugroho, A. D. (2019). Kajian pemanfaatan ruang kawasan pesisir studi kasus kawasan permukiman kumuh Kelurahan Padarni Kabupaten Manokwari. Cassowary, 2(2), 128-146. https://doi.org/10.30862/casssowary.cs.v2.i2.27

Peraturan Menteri Pekerjaan Umum dan Perumahan Rakyat Republik Indonesia Nomor 14/RT/M/2018 tentang Pencegahan dan Peningkatan Kualitas Terhadap Perumahan Kumuh dan Permukiman Kumuh.

Rijanta, R., Setiawan, B., \& Marfai, M. A. (2014). MODEL PERMUKIMAN KAWASAN TEPIAN SUNGAI KASUS : PERMUKIMAN TEPIAN SUNGAI KAHAYAN KOTA PALANGKARAYA Urban Riverside Settlement Model Case : Kahayan Riverside Settlement, Palangkaraya. Jurnal Pemukiman, 9(1), 17-27.

Sharma, A., Tiwari, G., \& Rao, K. R. (2020). Identifying mixed use indicators for including informal settlements as a distinct land use: Case study of Delhi. Transportation Research Procedia, 48(2019), 1918-1930. https://doi.org/10.1016/j.trpro.2020.08.224

Surat Keputusan (SK) Walikota Singkawang nomor: 600/70.A/PERUM-C Tahun 2016 Tentang Penetapan Lokasi Lingkungan Perumahan dan Permukiman Kumuh di Kota Singkawang. 